\title{
SOROEPIDEMIOLOGIA DE Toxoplasma gondii E Neospora caninum EM UMA POPULAÇÃO CANINA HOSPITALAR NO SUL DE MINAS GERAIS, BRASIL
}

(SEROEPIDEMIOLOGY OF Toxoplasma gondii AND Neospora caninum IN CANINE HOSPITAL POPULATION IN SOUTHERN MINAS GERAIS, BRAZIL)

\section{F. R. SOUZA ${ }^{1}$, J. P. FONSECA ${ }^{2}$, F. R. P. BRUHN ${ }^{2}$, J. M. BARBIERI ${ }^{3}$, J. R. LUCCI ${ }^{3}$, A. M. GUIMARÃES ${ }^{4 *}$}

Toxoplasma gondii (Apicomplexa: Sarcocystidae) é um protozoário que causa a toxoplasmose, zoonose cosmopolita de grande relevância em saúde pública. Embora a toxoplasmose canina possa provocar distúrbios neurológicos, a infecção nessa espécie tem como relevância epidemiológica o fato dos cães atuarem como animais sentinela para o risco de infecção da população humana. Neospora caninum, protozoário apicomplexa (Sarcocystidae), é responsável pela neosporose, doença parasitária cosmopolita que pode provocar distúrbios neuromusculares graves em cães, porém, se destaca por ser, atualmente, uma das principais causas de aborto e natimortalidade em bovinos, sem evidências de potencial zoonótico, até o momento. Este estudo observacional seccional teve como objetivo determinar a frequência de cães infectados por T. gondii e $N$. caninum, e associar o status sorológico a algumas variáveis epidemiológicas. Amostras de soros foram coletadas de 158 cães, de ambos os sexos, raças e idades variadas, atendidos no hospital veterinário da Universidade Federal de Lavras/MG, entre setembro de 2011 e março de 2012, independente do que tenha motivado a consulta. Para o cálculo da prevalência verdadeira, e seu intervalo de confiança a $95 \%$, foram considerados os valores de sensibilidade (SE) e especificidade (SP) da RIFI, com um ponto de corte 1:64 para $T$. gondii ( $\mathrm{SE}=80,4 \% ; \mathrm{SP}=91,4 \%)$ e 1:50 para $N$. caninum ( $\mathrm{SE}=99 \%$; $\mathrm{SP}=99 \%$ ). Na análise estatística, foi aplicado o teste de qui-quadrado para a seleção das variáveis utilizadas no modelo de regressão logística múltipla, ao nível de significância de 5\%. A frequência de cães soropositivos foi de 15,3\% (7,5\% - 24,9\%) para T. gondii e 11,9\% (7,3\% - 18,3\%) para N. caninum. Verificou-se que a única variável associada nos modelos finais de regressão logística foi a ocorrência de emagrecimento, sendo que cães nesta condição possuem maior chance de apresentar soropositividade a $T$. gondii $(\mathrm{p}=0,003$; $\mathrm{OR}=5,2 ; \mathrm{IC} 95 \%=1,7-15,7)$.

\section{Apoio: CNPq/MAPA e FAPEMIG}

\footnotetext{
${ }^{1}$ Graduanda em Medicina Veterinária, Universidade Federal de Lavras (UFLA)

${ }^{2}$ Mestre em Ciências Veterinárias, UFLA

${ }^{3}$ Mestrando em Ciências Veterinárias, UFLA

${ }^{4}$ Professor associado do Departamento de Medicina Veterinária, UFLA - amg@dmv.ufla.br
} 